\title{
Ontología del sentido y diferencia en la comunidad desobrada de Jean-Luc Nancy
}

\author{
Ontology of sense and difference \\ in the inoperative community of Jean-Luc Nancy
}

\author{
MARÍA GARCÍA PÉREZ \\ Universidad de Granada
}

Recibido: 02/06/16 Aceptado: 07/07/2016

\section{RESUMEN}

El pensamiento en torno a la noción comunidad de Jean-Luc Nancy presupone una ontología del sentido de herencia derridiana que profundiza en la idea del diferir y que tiene como objetivo último rebasar desde ahí a Heidegger y a Bataille ahondando en la senda abierta por ellos. Ahora bien, fundamentalmente es la línea de pensamiento teológico-político de Carl Schmitt el rival principal de las tesis del pensador francés. En síntesis, allí de lo que se trata es de oponer a toda comunidad cerrada, obrada, acabada, una comunidad abierta, inobrada e inacabada: una comunidad del diferir sin concesiones a la presencia.

\section{PALABRAS CLAVE \\ ONTOLOGÍA, COMUNIDAD, DIFERIR, TEOLOGÍA POLÍTICA}

\begin{abstract}
The thinking on Jean-Luc Nancy's community notion presupposes an ontology of sense of Derrida's heritage that explores the idea of differ and whose ultimate goal is to exceed from there to Heidegger and Bataille delving into the path opened for them. Having said that, basically is the line of thought of Carl Schmitt's political theology the main rival of the French thinker theses. In short, what it is about is to oppose to all gated community, wrought, finished,
\end{abstract}

(C) Contrastes. Revista Internacional de Filosofía, vol. XXII-N² (2017), pp. 91-106. ISSN: 1136-4076 Departamento de Filosofía, Universidad de Málaga, Facultad de Filosofía y Letras Campus de Teatinos, E-29071 Málaga (España) 
an open community, inoperative and unfinished: a community of differ without concessions to the presence.

\author{
KEYWORDS \\ ONTOLOGY, COMMUNITY, DIFFER, POLITICAL THEOLOGY
}

\title{
I. INTRODUCCIÓN
}

El GESTO DE NANCY en la tematización de su comunidad desobrada supone la inversión del esquema schmittiano: si en el alemán la política era llevada al plano de la existencia de modo que el poder soberano acaba por definirse como aquél capaz de decidir entre amigo y enemigo, esto es, de colocarse fuera del derecho para, proclamando el estado de excepción, fundar y conservar el derecho, $\mathrm{y}$, si esta decisión viene posibilitada por la intensidad de una asociación y una disociación (entre amigos, la primera; entre enemigos, la segunda) en tanto que el enemigo constituía la negación óntica de la existencia del soberano; en cambio, en Nancy de lo que se trata es de entender que la noción de comunidad, también pensada desde coordenadas ontológico-existenciales, se encuentra más allá de lo político y constituye su continua desfundación.

En este sentido cabe anticipar a modo introductorio que esta desfundación de la que hablamos en el francés es análoga a la Destruktion heideggeriana de la metafísica y, paralelamente, a nuestro juicio, sigue la estela de la deconstrucción derridiana intentando llevar a esta incluso más allá de sí. ${ }^{1}$ En efecto,

1 No es de extrañar a este tenor que Derrida dedicara todo un libro a reflexionar sobre algunas cuestiones del pensamiento de Jean-Luc Nancy. En efecto, en El tocar nos advierte ya desde su inicio de la importancia del pensamiento de este autor dedicándole hondas palabras: «he querido esbozar un primer movimiento para saludar a alguien, para saludarlo a él, a Jean-Luc Nancy. A alguien que piensa y escribe hoy como ninguno (...) esa obra es un gran acontecimiento y ofrece uno de los ejemplos capitales de ésta época: un pensamiento hiperbólico y probo a la vez, exigente hasta el último extremo, exacto, en una palabra, según un sentido distinto de la exactitud que él habrá sabido firmar, ante el cual se habrá comprometido, él Jean-Luc Nancy» (J. Derrida, El tocar, Jean-Luc Nancy, Buenos Aires: Amorrortu, 2011, p. 13). Por lo demás, allí Derrida nos sumergirá en un tipo de comprensión del tacto, del tocar, más allá de la apropiación y, así, de la presencia, esto es, de los sujetos que tocan, allí donde Nancy «nos convoca a lo intocable del tocar» (Ibid., p. 430) de lo cual nos ocuparemos más adelante. Del mismo modo podemos remitirnos también al encuentro entre ambos autores recogido en Diálogo entre Jacques Derrida y Jean-Luc Nancy, Revista anthropos: Huellas del conocimiento, Nº 205, 2004 (Ejemplar dedicado a: Jean-Luc Nancy. El cuerpo como objeto de un nuevo pensamiento filosófico y político), pp. $27-48$. 
como es sabido, para Heidegger la historia de la filosofía occidental habría incurrido en un constante olvido del ser, y así paralelamente para Nancy, la historia política occidental habría incurrido de modo análogo en un olvido del ser en común. La pregunta pues que hay que hacerse en este caso y que organiza la comunidad nancyana como comunidad ontológica, más profunda y fundamental que cualquier comunidad óntica, fáctica, o más explícitamente, obrada, es aquella que interroga por el ser en común o ser-con. Ahora bien, es justamente a partir de este ser en común que Nancy concibe al Dasein ya siempre, desde el origen, como Mitdasein. Este giro que va del ser-ahí-con al ser-con-ahí supone entender la comunidad como originaria del ser y productora de sentido, pero un sentido que, como veremos, sigue la línea derridiana de un diferir constante de modo que la comunidad es ya siempre una comunidad des-presente y por esto mismo desobrada, una «la comunidad de los otros» ${ }^{2}$ donde el singular será también desde el inicio un ser singular-plural.

A este respecto, y aun reconociendo su valor como pensador de la comunidad, para Nancy Bataille aparecerá desde aquí superado en cuanto a las rémoras de una supuesta metafísica del sujeto que este autor habría creído identificar en su obra. Por lo demás esta ontología del sentido es, también, una ontología materialista según el propio autor, esto es, una ontología de los cuerpos, de su con-tacto y su dis-posición que, así, invertirá el esquema de Descartes dando prioridad a la res extensa como fundamento y prueba de aquél ser-con. Con todo, nuestra prioridad en lo que sigue será demostrar esa herencia derridiana en las tesis de Nancy, una herencia que, como observaremos, es objeto de cierta crítica velada en orden a radicalizar las posiciones acerca del doble movimiento de la différence y de la différance. ${ }^{3}$

\section{Mito E INMANENCIA EN LAS COMUNIDADES OBRADAS}

Según Nancy el pensamiento comunitario desde la modernidad se habría movido siempre en base al presupuesto del humanismo. Esto explica a su vista que la comunidad haya sido pensada como comunidad obrada, esto es, como una comunidad que debía realizar, producir, la esencia del ser humano. Por tanto, nos dice Nancy, el humanismo no sería otra cosa que un inmanentismo que

2 J.-L. Nancy, La comunidad desobrada, Madrid: Arena Libros, 2001, p. 35.

3 Sin adentrarnos en la reflexión del autor franco-argelino en torno a fonologocentrismo y a la lógica oposicional que se deriva de él y que, a su vista, hay que rebasar, brevemente podemos apuntar que en la deconstrucción derridiana différence hace referencia al poder del signo material de repetirse en los más diversos contextos, de diferir en ellos, y, de este modo, a la ruptura interna de su identidad en lo que se refiere al sentido y su transmisión. Por su lado la différance tiene que ver con el diferir del tiempo, esto es, con el espaciamiento que elude el presente de manera que la presencia queda así arrojada a su des-presencia. $C f$. Sáez Rueda, L., Movimientos filosóficos actuales, Madrid: Trotta, 2001, p 441. 
habría atravesado todo proyecto comunitario del Occidente moderno, desde el liberalismo al comunismo. En el primero, en tanto pensamiento del individuo, se operaría una suerte de atomismo que dejaría al ente humano sin relación con el otro arrojándolo al trabajo de su propia esencia, hacia una pretensión de inmortalidad al cabo alienante que trataría de sobrepasar la conciencia de la propia finitud. ${ }^{4}$ Lo decisivo no obstante sería en él la ausencia de vínculo: el individuo se torna un «ab-soluto, perfectamente suelto, distinto y clausurado, sin relación». ${ }^{5}$ Apuntando ya hacia el momento prospectivo, para Nancy se haría indispensable en este punto, si queremos llegar a la comunidad, un clinamen, esto es, aquella idea epicúrea acerca de la inclinación de lo atómico hacia lo otro. Por lo demás las contradicciones a las que conduce el individualismo desde la metafísica del sujeto que lo sustenta mostrarían su impotencia toda vez que esta absolutez, esta soledad de lo que es sin relación, implica no obstante que este ser sea el único en su soledad. Porque, como argumenta nuestro autor, ¿acaso se puede estar sólo cuando no existen otros? Esta soledad mayúscula de lo absoluto remite entonces a una incoherencia que impugnaría todo pensamiento del individuo y nos obligaría a volver nuestra vista hacia la reflexión comunitaria. Ahora bien, desde la otra cara de la moneda, esto es, desde el comunismo, a pesar de guardar en sí las promesas de libertad y justicia colectivas, igualmente se ha entendido la comunidad como trabajo, como realización del para-sí, o, más en concreto, al ser humano como productor de cosas y, a través de ellas, de sí mismo. De este modo, más allá de las cuestiones históricas del comunismo real, habría acabado inevitablemente por apostatar de lo que él mismo buscaba. En efecto, «el esquema de la traición se revela insostenible en la medida en que es la base misma del ideal comunista la que acaba por aparecer tras su aspecto más problemático: a saber, el hombre, el hombre definido como productor (se podría decir también: el hombre definido, sin más), y fundamentalmente como productor de su propia esencia en las formas de su trabajo o en sus obras». ${ }^{6}$ Realizar la esencia de y por la comunidad es por tanto el camino más seguro, paradójicamente, para perderla.

Es así que la experiencia histórica ha mostrado, precisamente, la ineficacia de ambos modelos y, en consecuencia, instalados en este doble fracaso, la emergencia totalitaria y su latencia en las democracias actuales se entiende como resultado de una profunda melancolía con respecto a una comunidad perdida y aun por venir, por realizar. Por tanto bajo este esquema subyace la explicación de la causa de los grandes males que han asolado la historia de Occidente: una historia atravesada por la insistencia en la creación, en la obra de

4 Cf. J.-L. Nancy, La comunidad desobrada, loc. cit., p. 17.

5 Ibid., pp. 17-18.

$6 \quad$ Ibid., p. 14.

Contrastes vol. XXII-N² (2017) 
una comunidad que finalmente se revela como una «comunidad de muerte - o de muertos» ${ }^{7}$ y que, por este motivo, ha fracasado una y otra vez imprimiendo con ese revés nuevos impulsos para recrearla.

Detengámonos un momento porque, con todo lo anterior si lo leemos despacio, podemos quizá encontrar ya al menos un aspecto del vínculo específico, a nuestro juicio, de Nancy con Derrida: la comunidad obrada, se diría, la democracia de los iguales por su fraternización en un origen mítico, de la amistad, la justicia y el don cumplidos,${ }^{8}$ desbaratada por el descubrimiento de la différence y de la différance en la deconstrucción, habría tomado siempre el rumbo de un continuo intento de realización al cabo frustrado, esto es, de venida a presencia de la esencia de lo humano, por la cual el hombre se habría instalado en una lógica guerrera, de violencia y muerte. El por-venir en su despresencia tomado como condición de toda presencia, la escritura en tanto que más fundamental y posibilitadora de la voz aunque ya desboradada ésta una y otra vez por el exceso del diferir sin cese, aseguraría de este modo también la venida de los horrores prolongando la secuencia entre inmanentismo, realización u obrabilidad y totalitarismo, donde realizar la esencia y presentar el sentido se tornan análogos. La única vía, como veremos en adelante, de salida de esta encrucijada será para Nancy la de instalar definitivamente en la des-presencia a la verdadera comunidad sin concesiones a la presencia para resistirla, o, si se quiere, heideggerianamente, preservar al ser-con en su ocultamiento respecto de las comunidades obradas, ónticas.

«(E)s en efecto la inmanencia del hombre al hombre, o incluso es en efecto el hombre, absolutamente, considerado como el ser inmanente por excelencia, lo que constituye el escollo para un pensamiento de la comunidad. Una comunidad presupuesta como debiendo ser la de los hombres presupone a su vez que ella efectúa o que debe efectuar, como tal, íntegramente su propia esencia, que es ella misma el cumplimiento de la esencia del hombre. (...) Desde entonces, el vínculo económico, la operación tecnológica y la fusión política (en un cuerpo o bajo un jefe) representan o más bien presentan, ${ }^{9}$ exponen y realizan necesariamente por sí mismos esta esencia (...) Es lo que llamamos «totalitarismo», y que, tal vez, sería mejor denominar «inmanentismo», si no es necesario reservar

7 Ibid., p. 31.

8 Nos referimos aquí al tratamiento que Derrida ofrece cuando trata de rastrear el núcleo último de la filosofía política occidental con la tematización de la amistad desde la antigua Grecia, con Platón y Aristóteles y que atraviesa, tras su cristianización en la Edad Media, toda la historia del pensamiento político occidental moderno y sus democracias, desde Montaigne hasta Carl Schmitt y su par amigo/enemigo. Y, como no puede ser de otro modo, Derrida viene a dinamitar desde dentro aquella tradición para encontrar una noción de amistad infinita, por-venir. (J. Derrida, Políticas de la amistad seguido de El oído de Heidegger, Madrid: Trotta, 1998).

9 La cursiva es nuestra 
esta designación a ciertos tipos de sociedades o de regímenes, en vez de ver en ella, por una vez, el horizonte general de nuestro tiempo, que engloba también las democracias y sus frágiles parapetos jurídicos». ${ }^{10}$

El por-venir, por más que haya querido ser visto por Derrida como un diferir, si es condición de la presencia, aun excedida, esto es, del inmanentismo y de la muerte, de la comunidad como comunidad de muerte, disuade del originario ser-con y lo traiciona. En efecto, porque esta comunidad de la presencia, de la que luego desarrollaremos sus rasgos fundamentales derivados de la inmanencia por la que se encontraría atravesada, dice Nancy que «no se aleja, no está diferida: nunca tuvo por-venir; no podría ni advenir, ni formar un futuro». ${ }^{11}$ Hacer pues de aquél diferir no ya una condición sino una resistencia a la presencia, a la obra, esta es la divisa.

Pero prosigamos, porque el origen de aquella melancolía por la comunidad perdida y aun por venir lo sitúa Nancy ya en los albores del pensamiento político moderno y se haría obvio en el ejemplo de la obra de Rousseau, esto es, en el tránsito del estado de naturaleza del bon sauvage hacia la sociedad y la civilización el cual escenificaría la conciencia del doloroso extravío de una comunidad armónica y paradisíaca a la vez que empujaría a la confección del proyecto colectivo. Tal comprensión será la que recorrerá después toda la época romántica hasta Hegel. En efecto, Rousseau es «el primero que hace experiencia de la cuestión de la sociedad como inquietud dirigida hacia la comunidad, y como conciencia de una ruptura (tal vez irreparable) de esta comunidad. Esta conciencia será en lo sucesivo lo de los Románticos, y la del Hegel de la $\mathrm{Fe}$ nomenología del espíritu». ${ }^{12}$ Por ella la modernidad habría trazado un camino de horrores, de comunidades obradas, cerradas y homogéneas que, de suyo, exigían bien la muerte del otro, bien el sacrificio del sí mismo, tal y como lo acreditaron después la experiencia histórica de las dos guerras mundiales, el nazismo y el holocausto judío. Lograr la presencia, realizar la comunidad, es tanto como desarrollar una esencia que se piensa propia y a desplegar y, así, todo lo inesencial, todo lo heterogéneo, ha de ser eliminado en un ejercicio de purificación comunitaria histórico por la cual la comunidad se torna unión comulgante. Embebida de esencialismo, la comunidad porta así un principio de identidad que la organiza y procura su homogeneización. Así también, como ocurría en Derrida, la lógica oposicional que crea jerarquías excluyentes y violentas ${ }^{13}$ es puesta en cuestión.

10 J.-L. Nancy, La comunidad desobrada, op.cit., p. 16.

11 Ibid., p. 32.

12 Ibíd., p. 26.

13 «Una oposición de conceptos metafísicos (...) nunca es el enfrentamiento de dos términos, sino una jerarquía y el orden de una subordinación. La desconstrucción no puede limitarse o pasar inmediatamente a una neutralización: debe, mediante un doble gesto, una doble 
Y es justamente el romanticismo el encargado de anunciar la necesidad de la emergencia de un mito nuevo, porque el mito se encuentra para Nancy en el origen de las comunidades obradas, inmanentes. Lo será además porque en el romanticismo mora el cristianismo o, más en concreto, la consciencia melancólicamente cristiana acerca de la pérdida de lo divino ocurrida en la modernidad. Así es, porque la experiencia de lo divino en el cristianismo no es otra que la de esa inmanencia que gesta la comunión y, con ello, la salvación, una experiencia que ahora se piensa truncada y que observa el distanciamiento de Dios, su retirada del mundo de los hombres, abandonados a su suerte, a sus meras potencias.

«El pensamiento o el deseo de la comunidad bien podría entonces no ser más que la invención tardía que trató de responder a la dura realidad de la experiencia moderna: que la divinidad se retiraba infinitamente de la inmanencia, que el dios-hermano era él mismo en el fondo el deus absconditus (...) y que la esencia divina de la comunidad -o la comunidad en tanto que existencia de la esencia divina— era lo imposible mismo». ${ }^{14}$

En este punto del análisis se hace evidente que tendremos que retomar y confrontar siquiera brevemente la reflexión de Nancy con la schmittiana que colocaba a la soberanía del lado del Estado en una estrategia por recuperar esa inmanencia perdida, ahora transformada en trascendencia por medio del decisionismo sobre la excepción de su teología política que igualmente homogeneiza e imprime la obra mediante el par amigo-enemigo, la misma oposición que como ya hemos apuntado Derrida también quiso deconstruir. Es así que la soberanía en Nancy, desfondando lo político y caminando hacia una impolítica, ${ }^{15}$ será una nada inapropiable, pues, por parte de sujeto alguno, Estado o Führer, que, a su vez, mostrará la impotencia del mito para una verdadera reflexión comunitaria.

Pues bien, en él, en el mito, se entrecruzan política y poética, esto es, se trata del «pensamiento de una ficción fundadora, o de una fundación por la ficción $:^{16}$ el mito inaugura la comunidad, la funda sobre un relato que, desde la modernidad, presuponemos en su carácter ficcional. Y esta fundación, en-

ciencia, una doble escritura, practicar una inversión de la oposición clásica y un desplazamiento general del sistema. Sólo con esta condición se dará a la desconstrucción los medios para intervenir en el campo de las oposiciones que critica y que es también un campo de fuerzas no-discursivas» (Derrida, J., Márgenes de la Filosofía, Madrid: Cátedra, 1988, p. 371).

14 J.-L. Nancy, La comunidad desobrada, op.cit., p. 28.

15 Podemos aludir aquí al pertinente estudio de Galindo Hervás, A., Pensamiento impolítico contemporáneo, Madrid: Sequitur, 2015.

16 J.-L. Nancy, La comunidad desobrada, op.cit., p. 101. 
tendida ontológicamente como emergencia de sentido, presenta la esencia del humano y la realiza en la distribución simbólica y práctica de la comunidad justamente como voluntad de unión comulgante de la multitud y su multiplicidad, esto es, el mito es la representación de la comunidad en tanto que tal, de ahí su carácter ritual. Sin él no hay comunidad como comunidad obrada. Ahora bien, su idiosincrasia ficticia hace posible su interrupción y en ella hay que profundizar según Nancy, como veremos, mediante la literatura o сотиnismo literario. La conciencia moderna que llega hasta el estructuralismo ha entendido al mito no en tanto productor de verdades, del ser, sino por cuanto su función operatoria constituye eficazmente a las agrupaciones humanas. En este sentido, nos dice Nancy, él supone una «ontología de la ficción, o de la representación $»:^{17}$ el mito, ahora lo sabemos, es un mito. Así, la interrupción misma anida ya en su seno. Otro motivo por el cual la modernidad habría quedado teñida por aquella melancolía por la comunidad perdida que ya hemos descrito y que hay que deshacer.

Cabe preguntarse entonces de nuevo, ¿no late aquí el mismo diagnóstico que en Carl Schmitt? La modernidad como época de la secularización y de la neutralización que, sin embargo, no detiene el trabajo de lo político según el alemán, se traduce en Nancy en esta cuestión en torno al mito. Revitalizarlo, refundar lo político mediante el recurso a la teología pre-moderna a través del Leviathan hobbesiano desandando el camino secularizador para revelar su esencia tal y como pretende Schmitt no sería más que otra vuelta de tuerca en torno a las comunidades obradas.

Ahora bien, el francés aduce que «(n)ada se ha perdido» ${ }^{18}$ porque, en verdad, la comunidad no es un proyecto a realizar sino que es consustancial al ser mismo en tanto que tal y, en consecuencia, ella no debe surgir, no surge, de mito alguno. De lo que se trata, por tanto, es de dar cuenta de la primacía ontológica del ser-con como dimensión no obrable, ${ }^{19}$ deconstruida, desobrada, ontológica antes que óntica, des-presente antes que, y resistiendo al, presente. En efecto, como se ha dicho, la perspectiva existencial y deconstructora permite a Nancy establecer su comunidad desobrada como forma de resistencia perenne frente a toda comunidad obrada, incluso frente a las más terribles como la nazi o fascista: «ella es, en cierto sentido, la resistencia misma: es decir, la resistencia a la inmanencia». ${ }^{20}$ Resistencia frente a la muerte del otro, del heterogéneo, pero también resistencia de la propia comunidad a su acabamiento, una co-

17 Ibid., p. 104-105.

18 Ibid., p. 29.

19 Cf. Alfonso Galindo, La soberanía, de la teología política al comunitarismo impolítico, Murcia: Res Pública, 2003, p. 153.

20 J.-L. Nancy, La comunidad desobrada, op.cit., p. 68. 
munidad que, de ser arrojada únicamente a la inmanencia, a la obra del mito, acaba por autodestruirse incapaz ella misma de llevarse a cumplimiento. Este fue el destino de la Alemania nazi, el suicidio de una nación entera arrastrada por la pulsión a ejecutar el mito ario. ${ }^{21}$

Pero además, de este modo, también la muerte aparecerá a una luz distinta pues ésta ya no puede experimentarse bajo la posibilidad de un relevo en la propia comunidad, esto es, de una subsunción o sometimiento a ella hasta el propio aniquilamiento por mor de una esencia a realizar, una esencia colectiva y comulgante, sino como el sinsentido que verdaderamente es. Por eso la muerte no es, en esta comunidad inoperante, la muerte del sí mismo, sino, siempre y fundamentalmente, la muerte del otro. La muerte nos reenvía a la alteridad justamente por nuestra condición finita, porque el sujeto no puede decir ni ser consciente en su propio final. Pero esta muerte del otro a su vez interrumpe el reconocimiento y desbarata así toda metafísica del sujeto en el mismo momento en que «reconozco que no hay en la muerte del otro nada reconocible», ${ }^{22}$ esto es, en que ella no es apropiable por el sí mismo. Es de este modo que la finitud será una de las claves para la singularidad nancyana capaz de rebasar al sujeto en sus dos versiones, tanto al individuo y su soledad como al colectivo y su comunión homogeneizante, en suma, a toda pretensión operatoria para la comunidad. En efecto, la verdadera comunidad, la comunidad del originario ser-con, se (des)organiza a través de los confines de la singularidad finita por los que ésta siempre se encuentra ex-puesta, espaciada o compareciendo ante otras singularidades. De esto nos ocuparemos ahora en profundidad mediante el análisis de la categoría que nuestro autor remarca: être singulier pluriel.

Hasta aquí la clave consiste pues en entender que la comunidad no puede estar compuesta de sujetos, ni individuales ni colectivos y, de igual modo, en ella no puede haber aspiración alguna a la inmortalidad, es decir, a la permanencia de una supuesta esencia imperturbable a la que rendirse obrándola. Es en este sentido que el esquema comunitario de Nancy escapa a cualquier pretensión comulgante: la comunión acontece entre individuos cuya interioridad confluye en una suerte de unión que los identifica, que los hace idénticos a sí mismos y al otro, aun más, que los hace deudores, en su esencia, de una instancia mayor que es la de la comunión misma la cual los realiza y los reconoce. Es esta una comunidad homogénea en la que el sacrificio y la muerte se producen en aras de la propia unión, de su perduración, de su infinitud. Aquí lo heterogéneo, lo diferente, ha de ser eliminado para conservar la pureza de tal unión comulgante. Lo importante hasta el momento es la propuesta nancyana que consistirá en ofrecer su categoría del ser singular plural como revulsivo y resistencia a esta 
pulsión identitaria que imprime la inmanencia. La trascendencia de los singulares entre sí, su separación, no obstante comunicante en y por sus límites, se encontraría a la base de esta noción: «la comunidad es la trascendencia (que) no significa otra cosa, precisamente, que la resistencia a la inmanencia (a la comunión de todos o a la pasión exclusiva de uno o de algunos: a todas las formas y a todas las violencias de la subjetividad». ${ }^{23}$

\section{Ser Singular-Plural. Cuerpo y Sentido}

Así, nuestro autor no apelará ni a los individuos ni al colectivo sino que, para su comunidad, en lugar de a un sujeto, se remitirá a las singularidades, a «existencias singulares que no son sujetos, y cuya relación (...) no es una comunión, ni una apropiación de objeto, ni un reconocimiento de sí, ni aun siquiera una comunicación como se la entiende entre sujetos». ${ }^{24}$ Éstas, por una parte, a diferencia del individuo que para ser requiere emerger de un fondo informe y hacerse en un proceso de individuación, y, por otra, lejos de la lógica sujeto-objeto en que aquél interioriza a éste de modo que la alteridad queda neutralizada, no responden a ninguna obra u operación y garantizan la separación entre uno y otro singular así como su mutua apertura. Por tanto, la comunidad supone la exposición continua entre los seres singulares dada su finitud, la cual no busca trascenderse en la obrabilidad de la inmanencia: «Un ser singular aparece, en tanto que la finitud misma: en el fin (o en el comienzo), en el contacto la piel (o del corazón) de otro ser singular, en los confines de la misma singularidad que es, como tal, siempre otra, siempre compartida, siempre expuesta». ${ }^{25}$

En suma, Nancy propone una nueva ontología que entienda desde el principio al ser como ser-con y que, por tanto, instale la pluralidad en el origen mismo. Por ello nos habla de un être singulier pluriel: singular, en tanto que vinculado a la muerte (que es siempre la muerte del otro) y al nacimiento que le hace único $\mathrm{y}$, así, transido de sus propios límites, finito; pero también simultáneamente plural, por cuanto su aparecer consiste, por aquellos mismos confines que lo constituyen, siempre en su estar entre otros seres, en con-tacto, ex-puesto. Por esta pluralidad, pues, su actividad más propia es la del com-parecimiento: el ser, como ser-con, consiste en su constante comparecencia ante otros, en su apertura que toma la forma de una ex-posición, esto es, de un estar fuera de sí mismo: «lo que la comunidad me revela, al presentarme mi nacimiento y mi muerte, es mi existencia fuera de mí (...) La comunidad no toma el relevo de la finitud que expone. Ella misma no es, en suma, más que esta exposición (...) 
porque la finitud «es» comunitaria, y sólo ella es comunitaria». ${ }^{26}$ En síntesis, de lo que se trata es de comunicación, esto es, de una finitud comunicante en la ex-posición, en ese estar fuera. Pero, por este motivo, ésta no debe entenderse ya como comunicación intersubjetiva porque lo que Nancy pretende es ir un paso más allá cualificando al ser mismo, desde la ontología y el análisis existencial, como ser comunicante. El ser nunca es, pues, sí mismo, sino que será siempre un ser-con, una alteridad, una completa trascendencia que suspende la obra de la inmanencia.

Lo que sostenemos aquí es que, por todo ello, el sentido que emerge de este ser-con, se presenta siempre diferido, o más propiamente, el sentido constituye una no-presencia, o, si se quiere, una co-presencia, y, la comunidad, en perpetuo devenir, es siempre acontecimiento inobjetivable, inobrable y desobrante al mismo tiempo. La comunidad es una comunidad, pues, diferida, pero es este un diferir cuyo encargo, cuyo por-venir, no es otro que el de la detención de la obra, de la presencia y del sí mismo, sin concesiones. Extremar a Derrida, esta es la clave nancyana de fondo a nuestro juicio, porque, extremarlo a él, profundizarlo, es llevar a la comunidad al (no) lugar en que el sentido se vuelve sentido común, sentido diferido, com-partido en la ex-posición, desactivando de este modo la presencia y el principio de identidad: «El co-mismo y como tal, la co-presencia del ser, no resulta presentable (...). Se trata pues de 'dar el sentido' del ser-en-común según lo que es, a saber, en-común, o con, y no según un ser o una esencia de lo común: dar entonces el sentido del ser-con en el mismo con».27 Sólo así, como el propio Nancy reconoce en un paréntesis, podemos llegar a desfondar a Hegel, al romanticismo que vio en la comunidad el objetivo final del trabajo del Espíritu y su dialéctica:

«(L)a ontología de la comunidad no tiene otra tarea que la de radicalizar, o la de agravar hasta el desfondamiento, y por vía del pensamiento del ser y de su différe/ance, el pensamiento hegeliano del Sí mismo. (...) No hay comunión, no hay ser común, hay el ser en común (...) El sentido del ser no es común — sino que el en-común del ser transita todo el sentido. $\mathrm{O}$ aún: la existencia no es más que para ser compartida. Pero esta partición — que se podría designar como la aseidad de la existencia - no distribuye una sustancia ni un sentido común. No reparte más que la exposición del ser, la declinación del sí-mismo, el temblor sin rostro de la identidad expuesta: $n o s$ reparte». ${ }^{28}$

Además este diferir, tal y como ocurría también en Derrida, no sigue teleología o principio rector alguno, es puro devenir sin principio ni fundamento,

26 Ibid., p. 54.

27 J.-L. Nancy, Ser singular plural, Madrid: Arena Libros, 2006, pp. 55 y 71.

28 J.-L. Nancy, La comunidad desobrada, op.cit., p. 156. 
sin origen ni finalidad que subsuma la diferencia que inaugura cada vez, esto es, que impida la emergencia de un nuevo mundo surgido a cada instante, en la ex-posición y el con-tacto de todos los entes entre sí imprimiendo la pluralidad de los orígenes y barriendo al Uno, de nuevo, a la presencia, a la identidad. Por este motivo podemos entender además que Nancy argumente que la comunidad no es otra cosa que una suerte de anarquía originaria, en sentido etimológico, es decir, como an-arjé, equiparable a una «democracia nietzscheana (que) compromete en acciones, operaciones, combates (...) que permiten preservar rigurosamente la ausencia de arkhé (...). El kratein democrático, el poder del pueblo, es el poder en primer lugar de derrotar (faire échec) el arkhé y, en segundo lugar, de hacerse cargo, todos y cada uno, de la apertura infinita así expuesta». 29

Con esto Nancy sigue la máxima nietzscheana acerca de la muerte de Dios, esto es, de la ausencia de fundamento pero, también, como Derrida, de la transvaloración que invierte la jerarquía y convierte a la multiplicidad en el componente esencial del mundo, o más exactamente, que destruye toda jerarquía. ${ }^{30}$ Y en ello se traduce la ausencia de soberanía a la que apuntábamos al inicio: no hay soberano por cuanto no hay autoridad que detente soberanía alguna que no sea la del reparto mismo en y por los singulares. La soberanía «no es NADA» porque queda repartida, diferida y no remite a centro alguno que la aglutine. Por tanto, esta ontología deslegitima toda producción de sujeto soberano por un doble motivo: en tanto sujeto y en tanto portador en exclusiva de soberanía. Y en esto mismo consiste la justicia: en la composición repartida, diferida, del mundo: «La justicia es, por tanto, la remisión a cada existente de lo que le pertenece según su creación única, singular en su coexistencia con todas las otras creaciones»». 31

Para seguir avanzando en este punto no hemos de olvidar además que Nancy no habla tan sólo del hombre, sino de todos los seres y, aun más, de ellos en tanto que cuerpo. Por este motivo y como ya hemos apuntado, él mismo define su posición como la de una ontología materialista, o, como una «ontología del cuerpo (que) es la ontología misma». ${ }^{32}$ Se entiende con esto que la cualidad de la comunidad sea la extensión en el entrecruzamiento o toque del con en el ahi de los singulares, cuyo espacio se constituye pues como el

29 J.-L. Nancy, La verdad de la democracia, Madrid: Amorrortu, 2009, pp. 43-57.

$30 C f$, C. de Peretti, Jacques Derrida, texto y deconstrucción, Barcelona: Anthropos, 1989, p. 24: «Esta norma ideal, estos valores absolutos que Nietzsche ataca implacablemente y de los que anuncia la muerte irreversiblemente son también en cierto modo aquellos que Derrida denuncia, a su manera, como los propios de la metafísica de la presencia».

31 J.-L. Nancy, «Cosmos basileus» en La creación del mundo o la mundialización, Barcelona: Paidós Ibérica., 2003, p. 147.

32 J.-L. Nancy, Corpus, Madrid: Arena libros, 2003, p. 15. 
con-tacto de sus partes extra partes. La comunidad es, en definitiva, vínculo en el cruce de los cuerpos en el «entre» que los espacia. La exposición, el inevitable afuera, significa entonces entrelazamiento de los cuerpos, su tocarse, su co-presencia, pura relación de exterioridad en movimiento, en devenir, que se da como experiencia de afectación emotiva, de padecimiento, o, como dice Nancy, de conmoción en que «el ser sí mismo es necesariamente ser fuera, ser en el afuera, ser expuesto o extenso». ${ }^{33} \mathrm{El}$ cuerpo, esa parte denostada desde la cultura occidental y cristiana en pro del alma o el espíritu, es ahora en Nancy el fundamento infundado de la comunidad, ec-sistencia como ausencia de sentido y de esencia, o presencia como co-presencia ahi, exterior, difiriendo siempre de sí, viniendo siempre del afuera y, en consecuencia, siendo siempre un otro "indefinidamente otro, indefinidamente fuera». ${ }^{34}$ De la comunidad espiritual de la interioridad, pues, pasamos a una comunidad corporal o de la exterioridad en que el alma, la cartesiana res cogitans, no es más que cuerpo experienciando esa exterioridad, en que el sentido mismo es también cuerpo ex-puesto que toca otros cuerpos.

\section{Comunismo Literario}

Pero aun debemos decir más porque Nancy describe el reparto mismo, el -con en tanto que ex-posición, como literatura o escritura de manera que acaba por hablarnos de una comunidad literaria, o, más provocadoramente, de un «comunismo literario». Esta reflexión, de nuevo, no puede más que recordar hondamente a Derrida: si el mito (la voz del mito) suponía el esfuerzo por la venida a presencia de la esencia misma del humano, por su realización, la literatura, en cambio, supone una des-presencia por su inacabamiento, esto es, por su reparto ad infinitum entre autores y lectores. Por tanto, mientras que el mito procuraba la unión comulgante y otorgaba legitimidad a su emisor, la literatura por su parte realiza el reparto e interrumpe la pulsión mitificante impidiendo toda obrabilidad, toda venida a presencia así como todo principio de identidad. Se objetará, reconoce Nancy, que el mito es ya un texto y que, por tanto, no se ve cómo se le puede aplicar esta reflexión pues al cabo aparecerá contradictoria. Ahora bien, lo que tenemos es un doble movimiento del texto, o del mito, o de la literatura, una doble posibilidad: «la comunicación, en verdad, es sin límites, y el estar en común se comunica al infinito de las singularidades. (...) la comunicación «misma» es infinita entre los seres finitos. Siempre y cuando estos seres no quieran comunicarse mitos de su propia infinitud: pues si tal es el caso, desconectan al punto la comunicación». ${ }^{35}$ Así,

33 Ibid., p. 106.

34 Ibid., pp. 110-111.

35 J.-L. Nancy, La comunidad desobrada, op.cit., p. 124-125. 
por más que la literatura misma pueda elevarse a mito, su comunicación, como vemos, supondrá siempre la interrupción de aquél, su resistencia, en tanto que reparto. En consecuencia, aquélla interrupción no se da únicamente por su carácter ficcional descubierto en la modernidad sino que, más originariamente, se remonta al surgir mismo del mito pues, en suma, de lo que se trata es de comunicación. Por ello, esta comunidad es siempre una comunidad «por venir en el sentido de que viene siempre, sin cesar, en el seno de toda colectividad (y es porque no cesa de venir ahí por lo que resiste ahí sin fin a la colectividad misma tanto como al individuo)». ${ }^{36}$

Tenemos entonces dos voces. De un lado, la voz del mito como voz de la presencia y la inmanencia, la voz que procura los horrores del totalitarismo llevados a su cima en la experiencia histórica del nazismo, esto es, donde, atravesando la modernidad, encontramos ese inmanentismo como realización de una esencia perdida en el tiempo.

«(U)na co-pertenencia del pensamiento del mito, de la escenografía mítica, y de la puesta en obra y en escena de un «Volk» y un «Reich» en los sentidos que el nazismo dio a estos términos. (...) La idea del mito concentra tal vez ella sola toda la pretensión de Occidente de apropiarse de su propio origen, o de robarle su secreto, para poder identificarse al fin, absolutamente, en torno a su propia proferencia y a su propio nacimiento. La idea del mito presenta tal vez ella sola la Idea misma de Occidente, en su representación y en su pulsión permanentes de un regreso a sus propias fuentes para reengendrarse en ellas como el destino mismo de la humanidad». ${ }^{37}$

Y, de otro, la voz de la literatura como voz del diferir de la presencia, del sentido com-partido en su diferir; en suma, la voz del Uno como origen que quiere procurar la obrabilidad de la esencia del humano, y la voz del reparto, de los singulares y su origen siempre plural en tanto que originariamente son -co. Y la segunda supone siempre la interrupción de la primera en tanto que praxis del ser-con, esto es, en tanto que interrupción del sentido mismo.

Por otro lado, este rasgo lleva a Nancy a una reflexión sobre el tiempo y la historia. En efecto, nuestro autor entiende que la modernidad contemplaba la historia siempre orientada hacia un fin que, de algún modo, se dejaba ver ya en el inicio mismo, en el origen. La historia era así concebida por tanto como realización del eidos de una humanidad que, a su vez, se realizaba en ella. Ahora bien, frente a esta modernidad como era de la obra, desde la perspectiva de la comunidad del reparto la historia se muestra antes bien como historia nunca clausurada y siempre finita, una historia que, en todo caso, es la realización

36 Ibid., p. 133.

37 Ibid., pp. 88-89. 
de la existencia en su no tener más esencia que ella misma, esto es, como un estar fuera-de sí, siempre expuesta. Por tanto, «(1)a historia en su acaecimiento, es aquélla en la que nunca somos capaces de estar presentes, y eso es nuestra existencia y nuestro «Nosotros»»r. ${ }^{38}$ Es aquí donde podemos entender mejor la noción de espaciamiento que afecta al tiempo: ésta supone la apertura a un futuro sin telos ni finalidad, sin movimiento alguno de cumplimiento de una esencia o identidad previas. Y esto porque Nancy nos advierte que, en consecuencia, ya no podemos pensar el tiempo como mera sucesión, como linealidad de un pasado a un presente y a un futuro, regidos por la ley de la causalidad, por una permanencia que va de las causas a los efectos. Eliminar la presencia del tiempo, encontrar su diferencia, entraña advertir que en él ocurre siempre la alteridad del com-parecer de las existencias. Por eso el mundo es siempre un mundo com-partido en que el presente siempre está llegando, brotando de nada, y es ahí donde se cifra la libertad fuera, pues, de toda determinación.

En suma tenemos que, como en Derrida, el diferir no afecta sólo al sentido y su venida a presencia (différence), sino también al tiempo y su linealidad (différance). La comunidad desobrada, el -co inextricable a la existencia, implica entonces una justicia porvenir lejos de toda violencia como subsunción e imprime nuestra libertad más allá de toda determinación o de toda remisión a algún supuesto origen mítico. Observamos entonces claramente que la comunidad desobrada de Nancy guarda la línea derridiana y aun más, la profundiza, colocándonos en esa ontología del (diferir del) sentido para el pensamiento de la comunidad a través de sus categorías de ex-posición, de ser singular-plural y de cuerpo.

\section{BiBLIOGRAFÍA}

DE PERETTI C. 1989: Jacques Derrida, texto y deconstrucción, Barcelona. Anthropos.

DERRIDA J. 1988: Márgenes de la Filosofía, Madrid. Cátedra.

____ 1998: Políticas de la amistad seguido de El oído de Heidegger. Madrid. Trotta.

___ 2011: El tocar, Jean-Luc Nancy, Buenos Aires. Amorrortu.

2004: Diálogo entre Jacques Derrida y Jean-Luc Nancy, Revista anthropos: Huellas del conocimiento. $\mathrm{N}^{\mathrm{o}}$ 205. (Ejemplar dedicado a: Jean-Luc Nancy. El cuerpo como objeto de un nuevo pensamiento filosófico y político), pp. 27-48.

GALINDO HERVÁS A. 2003: La soberanía, de la teología política al comunitarismo impolítico. Murcia. Res Pública.

38 Ibid., p. 198. 
—__ 2015: Pensamiento impolitico contemporáneo. Madrid. Sequitur.

NANCY J.-L. 2001: La comunidad desobrada, Madrid. Arena Libros.

——_, 2003: Corpus, Madrid: Arena libros.

, 2003: «Cosmos basileus» en La creación del mundo o la mundialización, Barcelona. Paidós Ibérica

___ 2006: Ser singular plural, Madrid. Arena Libros.

___ 2009: La verdad de la democracia, Madrid. Amorrortu.

SÁEZ RUEDA L. 2001: Movimientos filosóficos actuales, Madrid. Trotta.

María García Pérez es Doctora por la Universidad de Granada

Lineas de investigación:

Ontología, pensamiento francés de la diferencia y filosofía política.

Publicaciones recientes:

«Resistencia e insurrección en Gilles Deleuze. Una respuesta a Toni Negri», Eikasía revista de Filosofia, 64, (2015), pp. 195-216

«Ontología en Georges Bataille», Aporía. Revista internacional de investigaciones filosóficas, 9, (2015), pp. 4-19

«Georges Bataille. Comunidad y comunicación», Res Publica. Revista de Historia de las Ideas Políticas, Vol. 17 Núm. 1 (2014), pp. 115-134

e-mail: themylam@gmail.com 